Simposium Nasional Akuntansi VIII. Solo, 15-16 September 2005.

Hapsoro, Dody. 2008 .Pengaruh Mekanisme Corporate Governance Terhadap Kinerja Perusahaan: Studi Empiris Di Pasar Modal Indonesia. Jurnal Akuntansi dan Manajemen Vol. 19, No. 3, Desember 2008.

Indriantoro, Nur dan Bambang Supomo.2002. Metodologi Penelitian Bisnis Untuk Akuntansi Dan Manajemen. Yogyakarta: BPFE.

Jensen, M., C., dan Meckling, W., H. 1976. Theory of the Firm: Managerial Behavior, Agency Cost, and Capital Structure. Journal of Financial Economics, 3:305.

John, K., Litov, L., dan Yeung, B. 2008. Corporate Governance and Risk-Taking. Journal of Finance, 63:1979.

Kusumawati, Eni dan Zulfa Irawati. 2013. Manajemen Keuangan. Surakarta: UMS

Kusumawardhani, Indra. 2012. Pengaruh Corporate Governance, Struktur Kepemilikan, dan Ukuran Perusahaan Terhadap Manajemen Laba. Jurnal Akuntansi dan Sistem Informasi Teknologi.Vol.9.No.1.

Meythi dan Lusiyana Devita. 2011. Pengaruh Penerapan Good Corporate Governance (GCG) Terhadap Kinerja Keuangan Perusahaan: Studi Empirik Pada Perusahaan Go Public Yang Termasuk Kelompok Sepuluh Besar Menurut Corporate Governance Perception Index (CGPI) Di Bursa Efek Indonesia. Dialogia Iuridicia, November 2011, Vol.3 No.1

Nuswandari, Cahyani. 2009. Pengaruh Corporate
Governance Perception Index Terhadap Kinerja Perusahaan Pada Persuahaan Yang Terdaftar Di Bursa Efek Jakarta. Jurnal Bisnis dan Ekonomi (JBE), September 2009, Hal. 79-84 Vol. 16, No. 2 (ISSN: 1412-3126).

Rohman, Abdul dan Tito Albi Utama. 2013. Pengaruh Corporate Governance Perception Index, Profitabilitas, Leverage, dan Ukuran Perusahaan Terhadap Nilai Saham. Diponegoro Journal of Accounting. Vol.2. No.2. hal 1-9.

Shah, Abid Ali.,Rehana Kouser.,Muhammad Aamir.,Ch.Mazhar Hussain. 2012. The Impact of The Corporate Governance and The Ownership Structure on The Firm's Financial Performance and its Risk Taking Behavior._International Research Journal of Finance and Economics. ISSN 1450-2887 Issue 93.

Ujiyantho, Muh. Arief dan Bambang Agus Pramuka. 2007. Mekanisme Corporate Governance, Manajemen Laba dan Kinerja Keuangan (Studi Pada Perusahaan go publik Sektor Manufaktur). Simposium Nasional Akuntansi X. Makasar 26-28 Juli 2007.

Umar, Husein. 1998. Manajemen Risiko Bisnis (Pendekatan Finansial dan Non Finansial). Jakarta: PT Gramedia.

http://iicg.org/v25/ diakses pada tanggal 7 November 2013 pukul 17.00

http://www.mitrariset.com/ diakses pada tanggal 16 Juli 2013 pukul 10.00

www.idx.com diakses pada tanggal 15 Oktober 2013 pukul 13.00 


\title{
PENGARUH IMPLEMENTASI SISTEM INFORMASI KEUANGAN DAERAH DAN KINERJA PEGAWAI: KUALITAS INFORMASI LAPORAN KEUANGAN SEBAGAI VARIABEL INTERVENING (STUDI EMPIRIS PADA SATUAN KERJA PERANGKAT DAERAH KABUPATEN BANYUMAS
}

\author{
Dona Primasari \\ Universitas Jenderal Soedirman \\ e-mail: dona_primasari@yahoo.com
}

\begin{abstract}
The objective of this research is to analyze the influence of effectiveness of regional financial information system to officer performance,with the quality of information of financial report as intervening variable.Data was collected by 61 officer of SKPD Banyumas. The analysis method used is AMOS ver.18.00 analysis, The result of the analysis shows: (1) a strong influence between effectiveness of regional financial information system to officer performance (2) a moderate influence between effectiveness of regional financial information system to officer performance with the quality of information of financial report.
\end{abstract}

Keyword: effectiveness of regional information accounting system, the quality of information of financial report, officer performance

\begin{abstract}
PENDAHULUAN
Dengan bergulirnya UU Nomor 22 tahun 1999 tentang Pemerintahan Daerah dan UU Nomor 25 tahun 1999 tentang Perimbangan Keuangan Pemerintahan Pusat dan Daerah, dan aturan pelaksanaannya, pemerintah mengeluarkan UU RI Nomor 33 tahun 2004 tentang Perimbangan Keuangan antara Pemerintah Pusat dan Pemerintah Daerah. Pembentukan UndangUndang tentang Perimbangan Keuangan antara Pemerintah Pusat dan Pemerintah Daerah ini dimaksudkan untuk mendukung pendanaan atas penyerahan urusan kepada Pemerintah Daerah yang diatur dalam Undag-Undang tentang Pemerintahan Daerah.
\end{abstract}

Sebagai pelaksanaan Undang-Undang Nomor 33 Tahun 2004 tentang Perimbangan Keuangan antara Pemerintah Pusat dan Pemerin- tah Daerah mengamanatkan adanya dukungan SIKD untuk menunjang perumusan kebijakan fiskal secara nasional serta meningkatkan transparasi dan akuntabilitas dalam pelaksanaan desentralisasi.

Sejak tahun 2002 ditetapkan Kepmendagri 29/2002 yang mengacu pada PP Nomor 105 tahun 2000 dan UU Nomor 25 tahun 1999 mengenai pengimplementasian model struktur otoritas baru dan rancangan sistem informasi akuntansi yang baru di seluruh Indonesia. Dengan adanya otonomi ini, daerah diberikan kewenangan yang luas untuk mengurus rumah tangganya sendiri dengan sedikit campur tangan pemerintah pusat. Pemerintah daerah mempunyai hak dan kewenangan yang luas untuk menggunakan sumber - sumber keuangan yang dimilikinya sesuai dengan kebutuhan dan aspirasi masyarakat yang berkembang di daerah. 
Pada masa pemerintahan sentralistik (orde baru), Sistem Informasi Keuangan Daerah (SIKD) di seluruh Indonesia diatur dalam undang-undang (UU) nomor 5 tahun 1974, dilengkapi dengan peraturan pemerintah (PP) nomor 6 tahun 1975. Atas tiga dasar aturan ini, pemerintah pusat menerbitkan Surat Keputusan Menteri Dalam Negeri No.900-099 tentang Manual Administrasi Keuangan Daerah (MAKUDA) pada tahun 1981 yang pada era sekarang di sebut Sistem Informasi Keuangan Daerah (SIKD). MAKUDA inilah yang akhirnya menjadi pedoman atau manual yang berfungsi sebagai SIKD yang harus dijalankan sama/ seragam bagi seluruh daerah di Indonesia. Implementasi dari Sistem informasi keuangan daerah diharapkan dapat memenuhi tuntutan dari masyarakat tentang transaparansi dan akuntabilitas dari lembaga sektor publik (Mardiasmo,2002). Rintangan penting untuk tercapainya kesuksesan dari suatu implementasi sistem yang baru adalah kurangnya perhatian pada faktor perilaku selama implementasi. Selain itu masih sedikit penelitian yang dilakukan dengan memperhatikan faktor-faktor perilaku selama tahap implementasi sistem baru serta pengaruh sistem tersebut terhadap kepuasan dan kinerja ( Cavallozo dan Ittner , 2004). Untuk itulah maka rumusan masalah yang dibuat untuk studi yang dilakukan ini adalah

1. Apakah implementasi Sistem Informasi Keuangan Daerah (SIKD) berpengaruh terhadap kinerja pegawai?

2. Apakah implementasi Sistem Informasi Keuangan Daerah (SIKD berpengaruh terhadap kinerja pegawai melalui informasi laporan keuangan yang berkualitas?

Sedangkan tujuan dari studi yang dilakukan ini adalah :

1. Untuk menguji dan memperoleh bukti empiris mengenai pengaruh Sistem Informasi Keuangan Daerah (SIKD) terhadap kinerja pegawai
2. Untuk menguji dan memperoleh bukti empiris mengenai pengaruh Sistem Informasi Keuangan Daerah (SIKD) terhadap kinerja pegawai melalui variabel informasi keuangan

Hasil studi ini diharapkan dapat memberikan kontribusi bagi pengembangan bidang akuntansi perilaku dan akuntansi sektor publik serta nantinya diharapkan dapat memberikan kontribusi praktis bagi pegawai SKPD khususnya di Kabupaten Banyumas sebagai masukan dalam mengevaluasi tahap implementasi sistem.

\section{REVIEW LITERATUR DAN HIPOTESIS}

\section{Sistem Informasi Keuangan Daerah (SIKD) dan Kinerja pegawai}

Dalam penelitian ini, penulis mengkaji pengaruh implementasi Sistem Informasi Keuangan Daerah terhadap kinerja para aparat pemda. Berdasarkan pasal 14 Bab III mengenai penyelenggarann Sistem Informasi Keuangan Daerah (SIKD) dikemukakan bahwa SIKD diselenggarakan untuk mendukung Pemerintah Daerah dalam penyusunan anggaran, pelaksanaan anggaran dan pelaporan keuangan daerah.

Dengan adanya implementasi SIKD tersebut diharapkan mampu meningkatkan kinerja para aparat pemda. Implementasi SIKD dalam mendorong objektivitas organisasi akan mengurangi pengembangan praktek penyelewangan. implementasi sistem dapat membantu peningkatan kegiatan operasional pegawai, mampu digunakan sebagai kontrol sistem dalam praktek kerja pegawai. Dengan demikian hipotesis dapat dirumuskan:

H1: Implementasi Sistem Informasi Keuangan Daerah berpengaruh terhadap kinerja pegawai 
Implementasi Sistem Informasi Keuangan Daerah, Kualitas Informasi laporan Keuangan, kinerja pegawai

Tujuan pelaporan keuangan pemerintah dalam Sistem Informasi Keuangan Daerah menurut Tim Pokja Evaluasi Pembiayaan dan Informasi Keuangan Daerah (2000: 11) adalah:

\section{a. Akuntabilitas}

Mempertanggungjawabkan pengelolaan sumber daya serta pelaksanaan kebijakan yang dipercayakan kepada unit organisasi pemerintah dalam rangka pencapaian tujuan yang telah ditetapkan melalui laporan keuangan pemerintah secara periodik

b. Manajerial

informasi keuangan yang berguna untuk perencanaan dan pengelolaan keuangan pemerintah serta memudahkan pengendalian yang efektif atas seluruh aset, hutang, dan ekuitas dana.

\section{c. Transparansi}

Menyediakan informasi keuangan yang terbuka bagi masyarakat dalam rangka mewujudkan penyelenggaraan pemerintahan yang baik.

Adanya implementasi Sistem Informasi Keuangan Daerah akan membantu menghasilkan informasi laporan keuangan yang berkualitas, informasi laporan keuangan yang berkualitas ini menjadi dasar para pegawai dalam pengambilan keputusan, khususnya pegawai tingkat atas serta dapat dijadikan alat ukur acuan kinerja sehingga dirumuskan hipotesis sebagai berikut:

$\mathrm{H} 2$ : Implementasi sistem informasi keuangan daerah berpengaruh terhadap kinerja pegawai melalui informasi laporan keuangan yang berkualitas.

\section{Kerangka Pemikiran Teoritis}

Kerangka pemikiran teoritis yang menjelaskan pengaruh implementasi Sistem Informasi Keuangan Daerah (SIKD) terhadap kinerja pegawai dengan dimediasi kualitas informasi laporan keuangan gambarkan sebagai berikut :

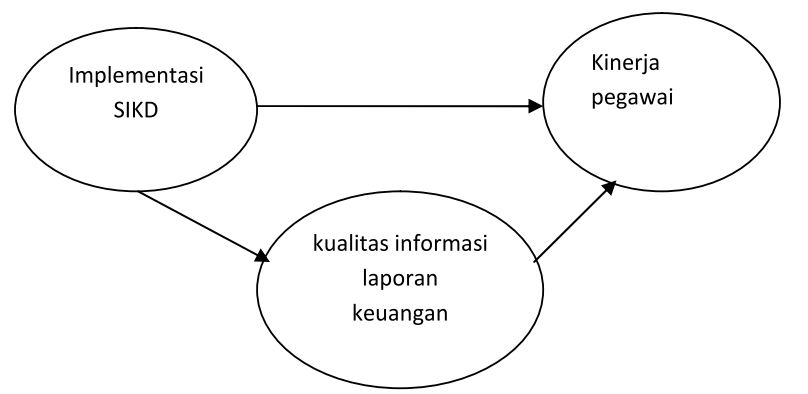

\section{Gambar 1 \\ Model kerangka teoritis}

\section{METODE PENELITIAN}

Jenis penelitian yang digunakan dalam penelitian ini adalah penelitian pengujian hipotesis (hypotheses testing) yaitu penelitian yang menjelaskan fenomena dalam bentuk hubungan antar variabel. Tipe hubungan antar variabel dalam penelitian ini adalah kausalitas yaitu tipe hubungan sebab akibat. Jenis data dalam penelitian ini adalah data subyek yaitu data penelitian yang berupa opini, sikap, pengalaman atau karakteristik dari seseorang atau sekelompok orang yang menjadi subyek penelitian (responden) (Indriantoro dan Supomo,1999). Sumber data yang dipergunakan dalam penelitian adalah data primer dalam bentuk persepsi responden (subyek) penelitian dan instrumen yang digunakan adalah kuesioner atau angket.

\section{Populasi, Sampel dan Teknik Pengambilan Sampel}

Populasi dalam penelitian ini adalah para Pegawai Daerah di Kabupaten Banyumas. Adapun sampel yang digunakan terdiri atas aparat pemda yang terlibat dalam rekontruksi rancangan dan penggunaan Sistem Informasi Keuangan Daerah (SIKD) meliputi sekretariat daerah, kepala badan, kepala dinas, kepala bagian, dan kepala seksi yang berkaitan dengan implementasi dan penggunaan SIKD (Syafruddin, 2005) di Kabupaten Banyumas Propinsi Jawa Tengah. Teknik pengambilan sampel dalam penelitian ini 
dilakukan dengan cara sensus sampling yaitu teknik penentuan sampel dengan mengambil semua sampel yang ada.

\section{Teknik Pengumpulan Data}

Pengumpulan data dilakukan dengan mail survey melalui penyebaran kuesioner dan mendatangi langsung wilayah sampel dalam penelitian yang dapat dijangkau (personally administered questionare). Bentuk kuesioner terdiri dari kuesioner dengan pertanyaan terkait (angket terstruktur). Data ini diperoleh melalui kuesioner yang dibagikan ke setiap responden. Responden menjawab pertanyaan yang diajukan pada kuesioner tersebut dan memilih satu yang paling tepat dari berbagai alternatif jawaban yang disediakan tanpa memberikan jawaban lain, kuesioner bentuk ini lebih menarik bagi responden karena kemudahannya dalam memberikan jawaban dan juga waktu yang digunakan untuk menjawab pertanyaan lebih singkat.

\section{Uji Kualitas Data}

Menurut Hair (1995) kualitas data yang dihasilkan dari penggunaan instrumen penelitian dapat dievaluasi melalui uji reabilitas dan validitas. Uji tersebut masing-masing untuk mengetahui konsistensi dan akurasi data yang dikumpulkan dari penggunaan instrumen. Ada dua prosedur yang dilakukan untuk melakukan reabilitas dan validitas, yaitu : uji konsistensi internal terhadap jawaban responden atas instrumen penelitian dan uji validitas konstruk dengan cara mengkorelasikan anatara skor masing-masing item dan skor totalnya. Keterangan dari kedua uji kualitas data adalah sebagai berikut:

1. Uji konsistensi internal (reliabilitas) ditentukan dengan koefisien cronbach alpha. Suatu konstruk atau instrumen dikatakan reliabel jika memberikan nilai cronbach alpha diatas 0.60 (Hair, 1995).
2. Uji homogenitas data (validitas) dengan uji pearson correlation. Jika hasilnya signifikan maka data tersebut dikatakan valid.

\section{Teknik Analisis}

Uji hipotesis menggunakan teknik Multivariate Structur Equation Model (SEM). Pemodelan SEM terdiri dari model pengukuran (measurement model) dan model struktural (struktural model). Model struktural ditujukan untuk menguji hubungan antara konstruk eksogen dan endogen. Sedangkan model pengukuran ditujukan untuk menguji hubungan antara indikator dengan konstruk / variabel laten Ballen (1989 ) dalam Imam Ghozali (2005). SEM dalam penelitian ini dianalisa menggunakan software AMOS.18.00

\section{HASIL PENELITIAN DAN PEMBAHASAN}

Dari seluruh jumlah kuesioner yang dibagikan yang kembali sebanyak 73 kuesioner, namun karena kurangnya kelengkapan pengisian kuesioner maka sebanyak 12 kuesioner tidak dapat diikut sertakan sehingga total jumlah kuesioner yang dapat diolah adalah 61 kuesioner

\section{Uji Kualitas data}

Berdasarkan uji kualitas data, diketahui data menunjukkan tingkat kekonsistenan dan keakurasian yang cukup baik. Pada uji reliabilitas, konsistensi internal koefisien Cronbach's Alpha menunjukkan tidak ada koefisien yang kurang dari nilai batas minimal 0,60 (Nunnally, 1967 dalam Imam, 2005). Sedangkan pada pengujian validitas dengan uji homogenitas data dan uji korelasional antara skor masing-masing butir dengan skor total (Pearson Correlation) menunjukkan korelasi yang positif dan tingkat signifikan pada level 0,01. 
Tabel 1

Hasil Uji Reliabilitas

\begin{tabular}{|c|l|c|c|}
\hline No & \multicolumn{1}{|c|}{ Variabel } & $\begin{array}{c}\text { Nilai } \\
\text { Cronbach } \\
\text { Alpha }\end{array}$ & Keterangan \\
\hline 1 & $\begin{array}{l}\text { Sistem Informasi Keuangan } \\
\text { Daerah }\end{array}$ & 0,752 & Reliabel \\
\hline 2 & $\begin{array}{l}\text { Kualitas Informasi Laporan } \\
\text { Keuangan }\end{array}$ & 0,764 & Reliabel \\
\hline 3 & Kinerja Pegawai & 0,808 & Reliabel \\
\hline
\end{tabular}

Sumber: data primer diolah 2012

Tabel 4.2

Hasil Uji Validitas

\begin{tabular}{|c|c|c|c|c|}
\hline No & Variabel & $\begin{array}{l}\text { Kisaran } \\
\text { Korelasi }\end{array}$ & Signifikansi & Keterangan \\
\hline 1 & $\begin{array}{l}\text { Sistem Informasi } \\
\text { Keuangan Daerah }\end{array}$ & $\begin{array}{l}0,674 * * \\
0,753 * *\end{array}$ & 0,001 & Valid \\
\hline 2 & $\begin{array}{l}\text { Kualitas } \\
\text { Informasi Laporan } \\
\text { Keuangan }\end{array}$ & $\begin{array}{l}0,618 * * \\
0,822 * *\end{array}$ & 0,001 & Valid \\
\hline 3 & Kinerja Pegawai & $\begin{array}{l}0,698 * * \\
0,773 * *\end{array}$ & 0,001 & Valid \\
\hline
\end{tabular}

Sumber: data primer diolah 2012

\section{Uji Normalitas}

Uji normalitas bertujuan untuk menguji apakah dalam model regresi, variabel pengganggu atau residual memiliki distribusi normal. Salah satu uji statistik yang dapat digunakan untuk menguji normalitas residual adalah uji statistik non-parametrik KolmogorovSmirnov (K-S). Nilai Kolmogorov-Smirnov (K$\mathrm{S})$ yang residual berdistribusi normal apabila nila Kolmogorov-Smirnovnya tidak signifikan pada 0,05 (karena $p>0,05$ ). Jadi tidak dapat menolak $\mathrm{H} 0$ yang mengatakan bahwa residual terdistribusi secara normal atau dengan kata laian residual berdistribusi normal (Imam, 2002).

Hasil uji normalitas data menunjukkan besar nilai Kolmogorov-Smirnov untuk variabel SIKD adalah 0.482 , variabel kualitas informasi laporan keuangan dan kinerja masing - masing adalah 0.475 dan 0.391 yang berarti $\mathrm{H}_{0}$ diterima yaitu data residual terdistribusi secara normal.

\section{Uji Hipotesis}

Ringkasan perbandingan model yang dibangun dengan cut of goodness of fit indices yang ditetapkan, nampak pada tabel 3 berikut :

Tabel 3

Goodness of fit indicates

Full model stuctural equation model setelah eliminasi

\begin{tabular}{|c|c|c|c|}
\hline $\begin{array}{c}\text { Goodness of } \\
\text { fit index }\end{array}$ & $\begin{array}{c}\text { Cut off } \\
\text { Value }\end{array}$ & $\begin{array}{c}\text { Hasil } \\
\text { Model }\end{array}$ & Keterangan \\
\hline Chi-Square & & 53.885 & \\
\hline Probabilitas & $\geq 0.05$ & 0.198 & Fit \\
\hline CMIN/DF & $\leq 2.00$ & 1.171 & Fit \\
\hline GFI & $\geq 0.90$ & 0.943 & Fit \\
\hline AGFI & $\geq 0.90$ & 0.904 & Fit \\
\hline TLI & $\geq 0.95$ & 0.985 & Fit \\
\hline CFI & $\geq 0.90$ & 0.989 & Fit \\
\hline RMSEA & $\leq 0.08$ & 0.034 & Fit \\
\hline
\end{tabular}

Sumber : Data dolah, 2012

Berdasarkan modifikasi model sebagaimana yang nampak tabel 3 yang menunjukkan goodness of fit indices yang baik. Yang mengindikasikan bahwa secara stastistik maupun secara teori model yang dibangun secara baik menjelaskan dan mendefinisikan variabel penelitian. Tingkat signifikansi probabilitas pada 0. 100 menunjukkan bahwa hipotesis nol yang menyatakan tidak ada perbedaan antara matrik dan kovarians sampel dengan matriks kovarian populasi yang diestimasi tidak dapat ditolak. Indeks-indeks lainnya juga menunjukkan tingkat penerimaan yang baik. Dengan demikian dari hasil model yang baik tersebut maka langkah selanjutnya dilajukan pengujian hipotesa.

Untuk menguji hipotesis yang diajukan, dapat dilihat besarnya Critical Ratio dan dan probabilitas pada output regression weight berikut pada tabel 4 
Tabel 4

Full Model Regression Weights

Regression Weights: (Group number 1 Default model)

\begin{tabular}{|ccc|ccccc|}
\hline & & & Estimate & S.E. & C.R. & P & Label \\
\hline ILK & $<---$ & SIKD & .925 & .123 & 6.123 & $* * *$ & par_5 \\
SIKD & $<---$ & ILK & .793 & 1.459 & .544 & .587 & par_13 \\
KNJ & $<---$ & SIKD & .775 & .289 & 2.753 & .006 & par_11 \\
KNJ & $<---$ & ILK & .111 & .165 & .797 & .563 & par_14 \\
x3 & $<---$ & SIKD & 1.000 & & & & \\
x6 & $<---$ & ILK & 1.000 & & & & \\
x8 & $<---$ & ILK & 1.341 & .133 & 7.679 & $* * *$ & par_1 \\
\hline
\end{tabular}

Sumber: Data diolah, 2012

Keterangan :

SIKD : Implementasi Sistem Informasi Keuangan Daerah

ILK : Kualitas Informasi Laporan Keuangan

KNJ : Kinerja Pegawai

Dari hasil output koefisien parameter dikemukakan penjelasan hipotesis sebagai berikut:

\section{Hipotesis 1}

Hipotesis pertama menyatakan bahwa implementasi SIKD berpengaruh terhadap kinerja. Dalam hasil pengolahan data menunjukkan parameter estimasi (standardized regression weight) ada pengaruh positif 0.289 dengan nilai critical ratio (CR) sebesar 2.753 dan nilai p-value 0.006. Nilai CR tersebut berada jauh di atas nilai kritis $\pm 1,96$ dengan tingkat signifikansi 0.006 (artinya signifikan) yaitu $p$ berada di bawah nilai signifikan 0,05 . Dengan demikian hipotesis pertama dapat diterima. Teori yang dikemukakan Macintosh (1994) bahwa penerimaan implementasi sistem merupakan bagian yang sangat pen-ting dalam spektrum mekanisme kontrol keseluruhan yang digunakan untuk memotivasi, me-ngukur, dan memberi sanksi tindakantindakan para manajer dan karyawan organisasi. Adanya penerimaan implementasi sistem mampu meningkatkan perencanaan dan kontrol akti- vitas organisasi dengan lebih baik sehingga meningkatkan kinerja.

Dalam lingkungan pemda peneriman implementasi SIKD akan meningkatkan efektivitas dan efisiensi sumber daya. Konsekuensi penerimaan implementasi SIKD dapat membantu pekerjaan lebih efisisen selaras dengan kesesuaian tugas, sehingga disimpulkan bahwa penerapan SIKD akan meningkatkan kinerja. Menurut Hunton (1996) penggunaan sistem informasi akan meningkatkan kinerja manajerial. Penerimaan implementasi sistem akan membantu para pegawai dalam melaksanakan kegiatan operasional kerja mereka, para pegawai cenderung akan memberdayakan implementasi sistem semaksimal mungkin sehingga secara otomatis akan meningkatkan kinerja mereka. Hasil ini juga sesuai dengan penelitian Arbenethy dan Jan Bouwens (2005).

\section{Hipotesis 2}

Hipotesis kedua menyatakan bahwa pengaruh implementasi Sistem Informasi Keuangan Daerah terhadap pegawai dimediasi oleh kualitas informasi laporan keuangan. Untuk mengetahui pengaruh tidak langsung penerimaan implementasi SIKD terhadap kinerja pegawai, dapat ditentukan dari penjumlahan pengaruh tidak langsung melalui kualitas informasi laporan keuangan. Pengaruh tidak langsung dihitung dari pengaruh langsung implementasi SIKD terhadap kualitas informasi laporan keuangan dikalikan dengan pengaruh langsung kualitas informasi laporan keuangan terhadap kinerja pegawai. Berdasarkan pada output standardized direct effect dan indirect effect output AMOS18.0 secara ringkas disajikan pada tabel 4.5 berikut ini.

Tabel 5

Standardized Direct Effect

\begin{tabular}{|l|c|c|c|}
\hline & SIKD & ILK & KNJ \\
\hline ILK & $\mathbf{1 . 0 4 1}$ & $\mathbf{0 . 0 0 0}$ & $\mathbf{0 . 0 0 0}$ \\
\hline KNJ & $\mathbf{0 . 0 0 0}$ & 0.120 & $\mathbf{0 . 0 0 0}$ \\
\hline
\end{tabular}

Sumber: Data diolah, 2012 
Pengaruh langsung adalah loading factor atau nilai lamda dari masing-masing indikator yang membentuk variabel laten yang dianalisis (Agusty, 2001). Untuk mengetahui pengaruh efektivitas implementasi SIKD terhadap kinerja pegawai melalui kualitas informasi laporan keuangan, dapat dilihat pada tabel 6.

\section{Tabel 6}

Pengaruh Tidak Langsung Implementasi SIKD Terhadap Kinerja Pegawai Melalui Kualitas Laporan Keuangan

\begin{tabular}{|c|c|c|c|}
\hline Jalur & $\begin{array}{c}\text { Pengaruh } \\
\text { langsung } \\
\text { SIKD-ILK }\end{array}$ & $\begin{array}{c}\text { Pengaruh } \\
\text { langsung } \\
\text { ILK-KNJ }\end{array}$ & $\begin{array}{c}\text { Pengaruh } \\
\text { tidak langsung } \\
\text { PISIKD-KP- } \\
\text { KNJ }\end{array}$ \\
\hline $\begin{array}{c}\text { SIKD- } \\
\text { ILK-KNJ }\end{array}$ & 1.041 & 0.120 & 0.125 \\
\hline
\end{tabular}

Sumber: Data diolah, 2012

Berdasarkan tabel 6 didapat dlilihat bahwa untuk jalur penerimaan implementasi SIKD terhadap kualitas informasi laporan keuangan sebesar 1.041. Nilai tersebut memberi makna bahwa semakin tinggi penerimaan implementasi SIKD maka semakin tinggi pula kualitas informasi laporan keuangan. Begitupun dengan jalur kualitas informasi laporan keuangan terhadap kinerja pegawai mempunyai pengaruh positif $(0.120)$ yang berarti semakin tinggi kualitas informasi laporan keuangan maka semakin tinggi pula kinerja pegawai.

Besarnya pengaruh tidak langsung pimplementasi SIKD terhadap kinerja pegawai melalui kualitas informasi laporan keuangan sebesar 0.125 . Tanda positif tesebut memberi makna bahwa kualitas informasi laporan keuangan terbukti memediasi antara implementasi SIKD dan kinerja pegawai. Adanya implementasi Sistem Informasi Keuangan Daerah akan membantu menghasilkan informasi laporan keuangan yang berkualitas, informasi laporan keuangan yang berkualitas ini menjadi dasar para pegawai dalam pengambilan keputusan, khususnya pegawai tingkat atas serta dapat dijadikan alat ukur acuan kinerja.

\section{KESIMPULAN DAN SARAN}

\section{Kesimpulan}

Berdasarkan hasil analisis data dan pengujian hipotesis, maka ditarik kesimpulan sebagai berikut:

1. Implementasi SIKD tebukti berpengaruh terhadap kinerja. Hal ini mendukung penelitian Igbaria dan Tan (1997) yang menemukan bahwa kepuasan pengguna atas teknologi informasi memiliki efek langsung atas kinerja. Hasil ini juga sesuai dengan penelitian Arbenethy dan Jan Bouwens (2005).

2. Terdapat pengaruh antara implementasi Sistem Informasi Keuangan Daerah dan kinerja pegawai melalui kualitas informasi laporan keuangan. Adanya implementasi Sistem Informasi Keuangan Daerah akan membantu menghasilkan informasi laporan keuangan yang berkualitas, informasi laporan keuangan yang berkualitas ini menjadi dasar para pegawai dalam pengambilan keputusan, khususnya pegawai tingkat atas serta dapat dijadikan alat ukur acuan kinerja.

\section{Saran}

Penelitian ini bisa diperluas dengan menambah beberapa variabel pendukung lainnya, karena dalam penelitian ini hanya digunakan satu variabel intervening sehingga tidak cukup kompleks memberikan gambaran dampak implementasi SIKD.

\section{DAFTAR PUSTAKA}

Abernethy, M. A., and Jan Bouwens. 2005. “ Determinants of accounting innovation". ABACUS. 
Ajzen, and Fishbein. 1975. "The theory of planned behavior organizational behavior and human decision process". Journal of Applied Social Psychology. Vol.32.

Cavalluzzo, K. S., and C. D. Ittner. 2004. "Implementing Performance Measurement

Innovations: Evidence From Government". Accounting, Organizations and Society, Vol. 29, Nos 3-4.

David, Effendi. 2001. " Pengaruh informasi akuntansi terhadap kinerja manajer dengan ketidakpastian tugas sebagai variable moderating (Studi pada Pemda Eks Karisidenan Madiun)". Program studi Magister Sains Akuntansi Universitas Diponegoro Semarang (tidak dipublikasikan).

Gatot, Indra.2005. "Penerapan Sistem Informasi Keuangan Daerah di Indonesia". CV.Duta Nusindo. Semarang

Hair, J.R., Anderson, R.E., Tatham,R.L., Black,W.C. 1998. "Multivariate Data Analyst". Fifth edition. Prentice Hall International.Inc.

Honeman, C.T. 1997. "Introduction to managerial performance”. Prentice Hall.

Igbaria, M., and M. Tan. 1997. "The Consequences of Information Technology Acceptance on Subsequent Individual Performance". Information and Management, Vol. 21, No. 3.

Indra Bastian.2002. "Akuntansi sektor publik di Indonesia”. BPFE Yogyakarta.
Imam Ghozali. 2008. "Model persamaan structural , konsep dan aplikasi dengan program AMOS Ver.18”. Badan Penerbit Universitas Diponegoro, Semarang.

Kaplan, R. S. 1986. "Accounting Lag: The Obsolescence of Cost Accounting Systems".California Management Review, Vol. 28, No. 2.

Lyna Latifah, 2005. "Pengaruh faktor organisasional, peran konflik kognitif dan afektif dalam tahap awal implementasi system keuangan daerah". Program Magister Akuntansi Universitas Diponegoro, Semarang (tidak dipublikasikan).

Mardiasmo.22 Maret 2001. "Perencanaan keuangan public sebagai suatu tuntutan dalam pelaksanaan pemerintahan daerah yang bersih dan berwibawa". Makalah seminar IAI-KASP. Jakarta.

Mardiasmo. 2000. "Akuntansi sektor publik". Andi Yogyakarta.

Miah, N.Z and Mia L. 1996. "Desentralitation, Accounting control system and Performance of Government Organization : A new Zaeland Empirical Study". Financial Accountability and management.

Peraturan Pelaksanaan UU Perimbangan Keuangan antara Pemerintahan Pusat dan

Daerah. 2006. Penerbit CV. Duta Nusindo, Semarang. 